\title{
Erratum to "Circulating Levels of MicroRNA from Children with Newly Diagnosed Type 1 Diabetes and Healthy Controls: Evidence That miR-25 Associates to Residual Beta-Cell Function and Glycaemic Control during Disease Progression"
}

\author{
Lotte B. Nielsen, ${ }^{1,2}$ Cheng Wang, ${ }^{3}$ Kaspar Sørensen, ${ }^{4}$ Claus H. Bang-Berthelsen, ${ }^{5}$ \\ Lars Hansen, ${ }^{1,2}$ Marie-Louise M. Andersen, ${ }^{1,2}$ Philip Hougaard, ${ }^{6}$ \\ Anders Juul, ${ }^{4}$ Chen-Yu Zhang, ${ }^{3}$ Flemming Pociot, ${ }^{5}$ and Henrik B. Mortensen ${ }^{1,2}$ \\ ${ }^{1}$ Department of Pediatrics, Herlev Hospital, 2730 Herlev, Denmark \\ ${ }^{2}$ Faculty of Health Sciences, University of Copenhagen, 2200 Copenhagen, Denmark \\ ${ }^{3}$ Jiangsu Engineering Research Center for microRNA Biology and Biotechnology, State Key Laboratory of Pharmaceutical Biotechnology, \\ School of Life Sciences, Nanjing University, Nanjing 210093, China \\ ${ }^{4}$ Department of Growth and Reproduction, Rigshospitalet and Faculty of Health Sciences, University of Copenhagen, \\ 2100 Copenhagen, Denmark \\ ${ }^{5}$ Glostrup Research Institute, Glostrup Hospital and Center for Non-Coding RNA in Technology and Health, University of Copenhagen, \\ 2600 Glostrup, Denmark \\ ${ }^{6}$ Department of Statistics, University of Southern Denmark, 5000 Odense, Denmark
}

Correspondence should be addressed to Lotte B. Nielsen, lnie0342@regionh.dk

Received 12 September 2012; Accepted 20 September 2012

Copyright (c) 2012 Lotte B. Nielsen et al. This is an open access article distributed under the Creative Commons Attribution License, which permits unrestricted use, distribution, and reproduction in any medium, provided the original work is properly cited.

The following sentence: Furthermore, miR-25 one month after diagnosis was positively associated with residual betacell function $(P=0.0037)$, and negatively associated with glycaemic control (HbAlc) $(P=0.0035) 3$ months after disease onset, should replace this sentence in the abstract of the existing paper: Furthermore, we identified miR-25 as negatively associated with residual beta-cell function (est.: $-0.12, P=0.0037)$, and positively associated with glycaemic control (HbA1c) (est.: 0.11, $P=0.0035) 3$ months after onset. 


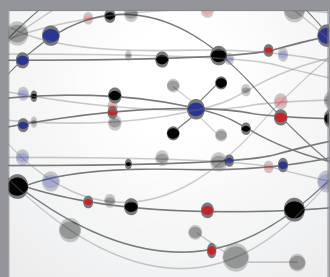

The Scientific World Journal
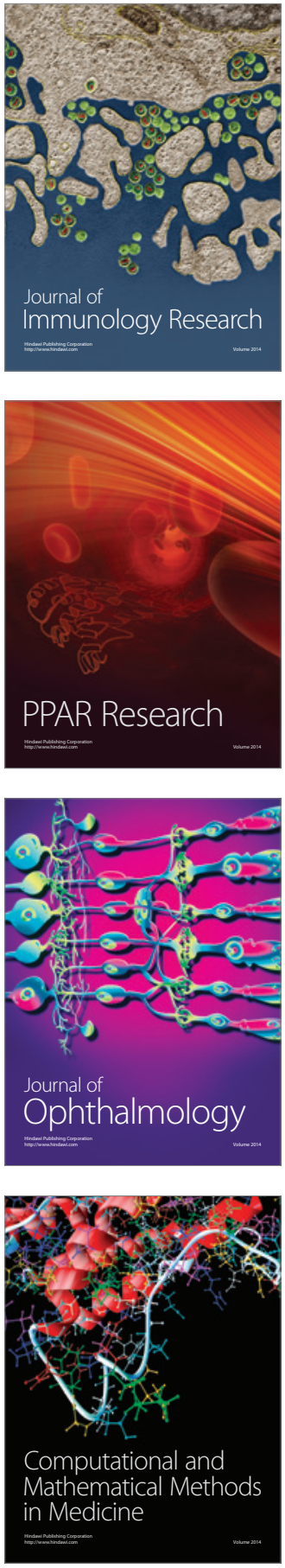



Gastroenterology

Research and Practice


\section{Hindawi}

Submit your manuscripts at

http://www.hindawi.com
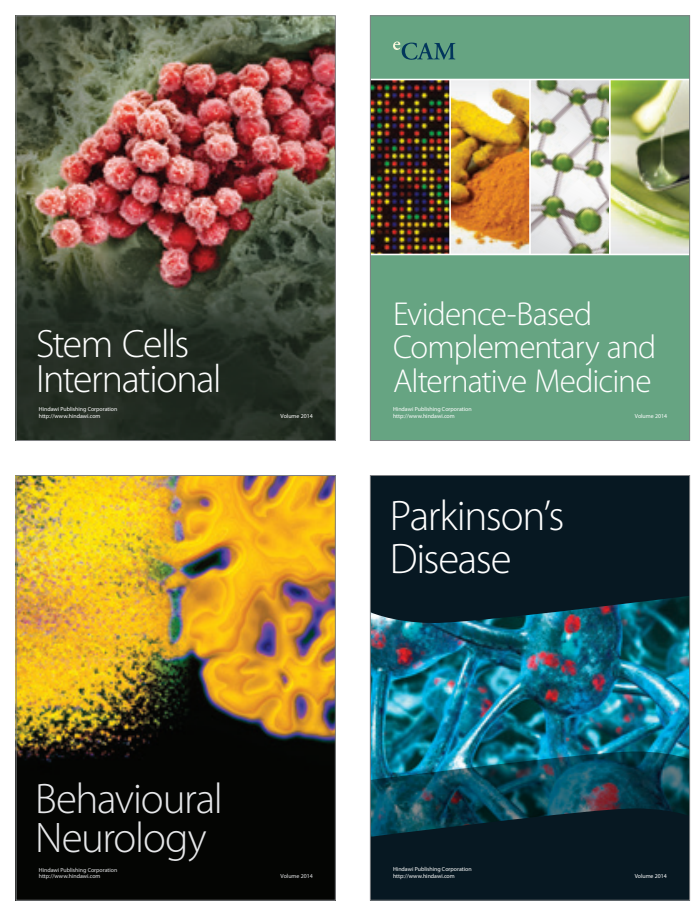

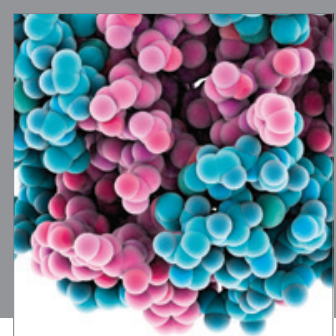

Journal of
Diabetes Research

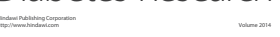

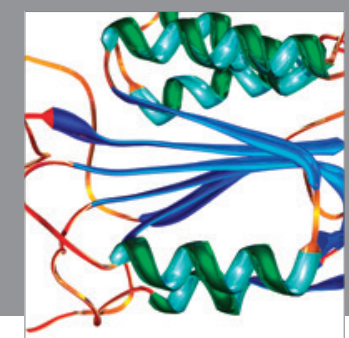

Disease Markers
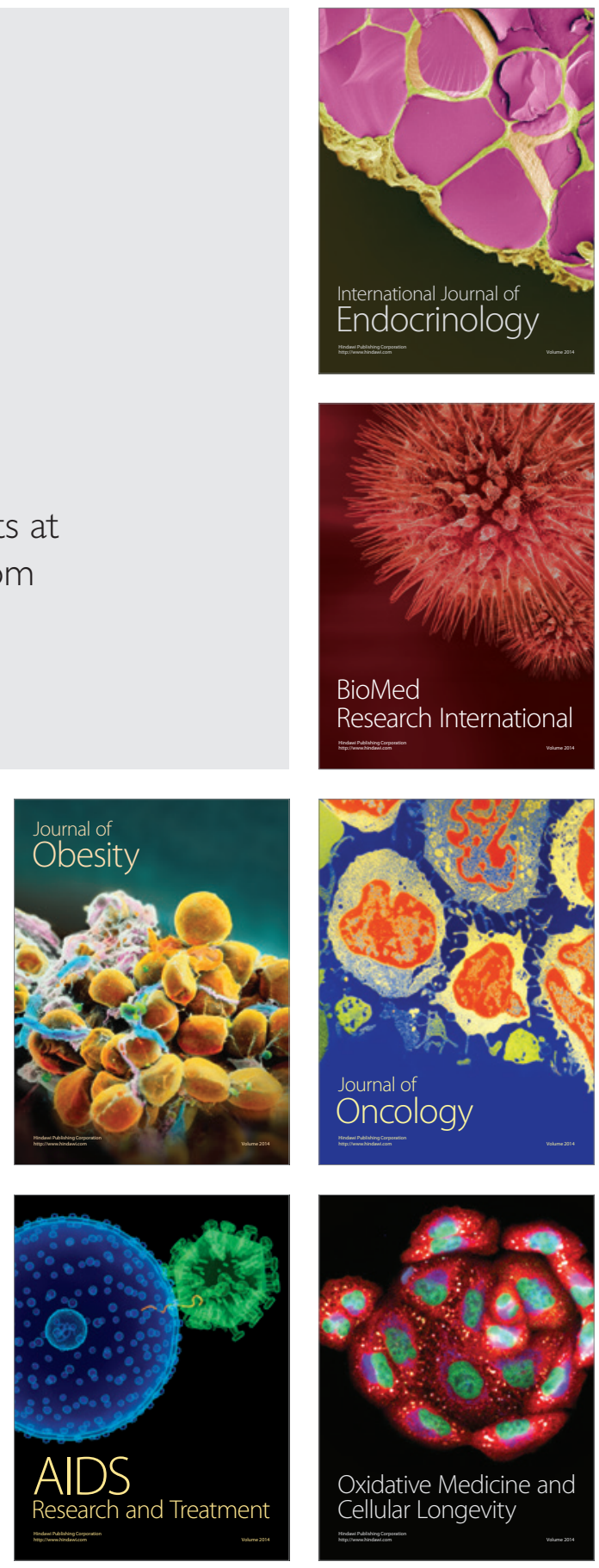